Cite this: Org. Biomol. Chem., 2014, 12,3831

Received 21st March 2014, Accepted 17th April 2014

DOI: $10.1039 / \mathrm{c} 4$ ob00609g

www.rsc.org/obc

\section{First total syntheses of chrestifoline-B and $( \pm)$-chrestifoline-C, and improved synthetic routes to bismurrayafoline-A, bismurrayafolinol and chrestifoline-Dit}

\author{
Carsten Börger, Arndt W. Schmidt and Hans-Joachim Knölker*
}

We describe an efficient synthesis of the methylene-bridged biscarbazole alkaloids bismurrayafoline-A, bismurrayafolinol and chrestifoline B-D using an Ullmann-type coupling at the benzylic position.

A wide range of carbazole alkaloids has been isolated and investigated towards their biological activity. ${ }^{1-3}$ Much less is known about the pharmaceutical potential of biscarbazoles and only a few synthetic approaches have been described.,4 We have developed several methods for the synthesis of carbazoles. ${ }^{1,2}$ Using our palladium-catalysed construction of the carbazole framework, ${ }^{5}$ we recently described efficient synthetic routes to biscarbazole alkaloids, ${ }^{6-8}$ for example the oxygenbridged biscarbazole oxydimurrayafoline and the $\mathrm{N}$-aryl linked murrastifoline-A. ${ }^{7,8}$ The biscarbazole linkage was constructed by etherification, ${ }^{7}$ the Buchwald-Hartwig amination, ${ }^{9}$ or the Ullmann coupling. ${ }^{10}$ Herein, we report the synthesis of methylene-bridged biscarbazole alkaloids by palladium(0)- and copper(I)-catalysed coupling reactions at the benzylic position at C-3 of the carbazole framework.

The first methylene-bridged biscarbazole alkaloid obtained from natural sources was bismurrayafoline-A (1), isolated in 1983 by Furukawa et al. from the root bark of Murraya euchrestifolia Hayata (Fig. 1). ${ }^{11}$ Bismurrayafoline-A (1) showed a weak activity against some cancer cell lines. ${ }^{12}$ In 2001, Bringmann et al. reported the formation of bismurrayafoline-A (1) in up to $19 \%$ yield as a by-product of the reduction of mukonine (6d) (7 steps, 9\% overall yield of 1 ). ${ }^{13}$ We have described a total synthesis of bismurrayafoline-A (1) via an unprecedented rearrangement during an Ullmann coupling (6 steps, 28\% overall yield of 1). ${ }^{8}$ In 1987, Furukawa et al. isolated bismurrayafolinol (2) from the root bark of Murraya euchrestifolia Hayata. ${ }^{14}$ Bringmann et al. reported the formation of bismur-

Department Chemie, Technische Universität Dresden, Bergstrasse 66, 01069 Dresden, Germany.E-mail: hans-joachim.knoelker@tu-dresden.de

$\dagger$ Part 117 of Transition Metals in Organic Synthesis; for Part 116, see ref. $6 b$. \$Electronic supplementary information (ESI) available: ${ }^{1} \mathrm{H}$ and ${ }^{13} \mathrm{C}$ NMR spectra of the biscarbazole alkaloids 1-5. See DOI: 10.1039/c4ob00609g

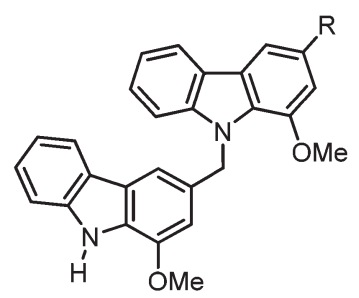

1 Bismurrayafoline-A $(\mathrm{R}=\mathrm{Me})$ 2 Bismurrayafolinol $\left(\mathrm{R}=\mathrm{CH}_{2} \mathrm{OH}\right)$ 3 Chrestifoline-D

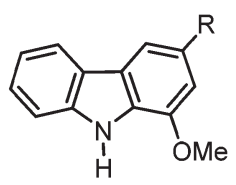

6a Murrayafoline-A $(R=M e)$

6b Koenoline

6c Murrayanine

6d Mukonine

$$
\begin{aligned}
& \left(\mathrm{R}=\mathrm{CH}_{2} \mathrm{OH}\right) \\
& (\mathrm{R}=\mathrm{CHO})
\end{aligned}
$$$$
(\mathrm{R}=\mathrm{COOMe})
$$

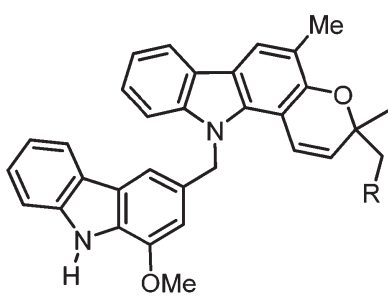

4 Chrestifoline-B $(\mathrm{R}=\mathrm{H})$ 5 Chrestifoline-C ( $R=$ prenyl)

Fig. 1 Bismurrayafoline-A (1), bismurrayafolinol (2), chrestifoline-B (4), chrestifoline-C (5), chrestifoline-D (3), the 1-methoxycarbazole alkaloids $6 a-d$, girinimbine (7a) and mahanimbine (7b).

rayafolinol (2) as a by-product in up to 6\% yield (7 steps, 3\% overall yield of 2) during their synthesis of murrayafoline-A (6a). ${ }^{13}$ Chrestifoline-D (3) was isolated in 1992 by Furukawa and Wu et al. from the root bark of M. euchrestifolia. ${ }^{15}$ The first synthetic approach by partial synthesis starting from bismurrayafolinol (2) was reported along with the isolation. Chrestifoline-B (4) and chrestifoline-C (5) were isolated in 1990 by Furukawa et al. from the same natural source. ${ }^{16}$ ChrestifolineC (5) has been obtained in an optically active form $\left([\alpha]_{\mathrm{D}}=\right.$ $\left.-5.6, \mathrm{CHCl}_{3}\right),{ }^{16}$ but its absolute configuration is not known.

The biscarbazoles 1-5 have an identical benzylic subunit which corresponds to murrayafoline-A (6a), but they differ in the benzylic substituent (Fig. 1). For the biscarbazoles 1-3, the benzylic linkage leads to the nitrogen atom of a 1-oxygenated tricyclic carbazole corresponding to murrayafoline-A (6a), koenoline (6b) or murrayanine $(\mathbf{6 c})$, respectively. For chrestifo- 
line-B (4) and chrestifoline-C (5), the pyrano[3,2-a]carbazole alkaloids girinimbine (7a) and mahanimbine (7b) serve as benzylic substituents. The mono-carbazole building blocks of the biscarbazoles 1-5 are found in nature as well. The 1-methoxycarbazole alkaloids, murrayafoline-A (6a), koenoline (6b), murrayanine (6c) and mukonine $(\mathbf{6 d})$, have been obtained from diverse plants of the Rutaceae family. ${ }^{1}$ The pyrano[3,2- $\left.a\right]$ carbazole alkaloids girinimbine (7a) and mahanimbine (7b) were isolated first by Chakraborty et al. from Murraya koenigii Spreng. ${ }^{17,18}$ Our group previously described synthetic routes to all individual carbazole fragments present in the biscarbazoles 1-5. An efficient iron-mediated synthesis of the 1-methoxycarbazole alkaloids 6a-d was reported early on. ${ }^{7,19}$ More recently, an optimised palladium-catalysed synthesis of mukonine (6d) was described. ${ }^{7}$ Several synthetic routes to girinimbine (7a) and an efficient access to mahanimbine (7b) were also developed by our group. ${ }^{20}$

For the synthesis of the biscarbazoles 1-5 we envisaged a retrosynthetic cleavage of the $\mathrm{C}-\mathrm{N}$ linkage between both carbazole units which leads to the carbazoles $\mathbf{8}$ and $\mathbf{9}$ as precursors (Scheme 1). In our approach the nitrogen atom of carbazole 8 serves as a nucleophile. Thus, carbazole $\mathbf{8}$ is represented by the unprotected naturally occurring carbazoles $\mathbf{6 a - c}, 7 \mathbf{a}$ and 7b. The fragment 9 should have a leaving group at the benzylic position and would be represented by an appropriate koenoline derivative. Compound 9 can be prepared from mukonine (6d) which is readily available using the arylamine $\mathbf{1 0}$ as the starting material. ${ }^{7}$

The Buchwald-Hartwig coupling of bromobenzene and arylamine $\mathbf{1 0}$ in the presence of SPhos followed by palladium(II)catalysed oxidative cyclisation afforded mukonine (6d) in 91\% yield over both steps (Scheme 2). ${ }^{7}$ Boc-protection of $\mathbf{6 d}$ and subsequent reduction of the ester group led to the protected koenoline 11. Next, the hydroxy group had to be transformed into a leaving group. However, in light of the high reactivity of
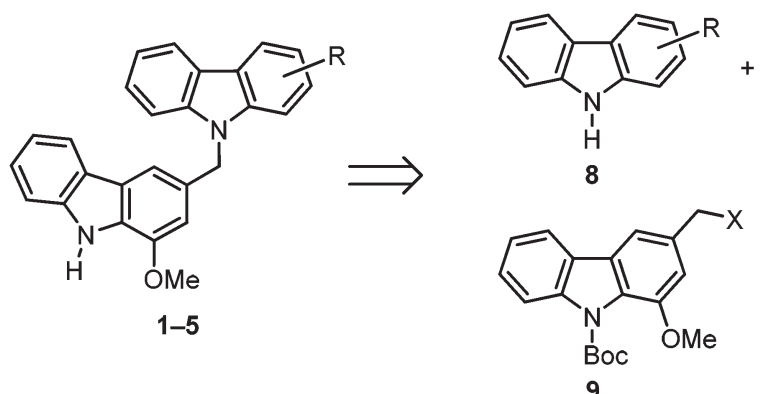

$\downarrow$

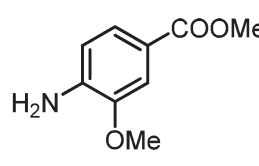

10

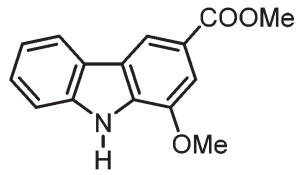

6d
Scheme 1 Retrosynthetic analysis of the methylene-bridged biscarbazoles 1-5.
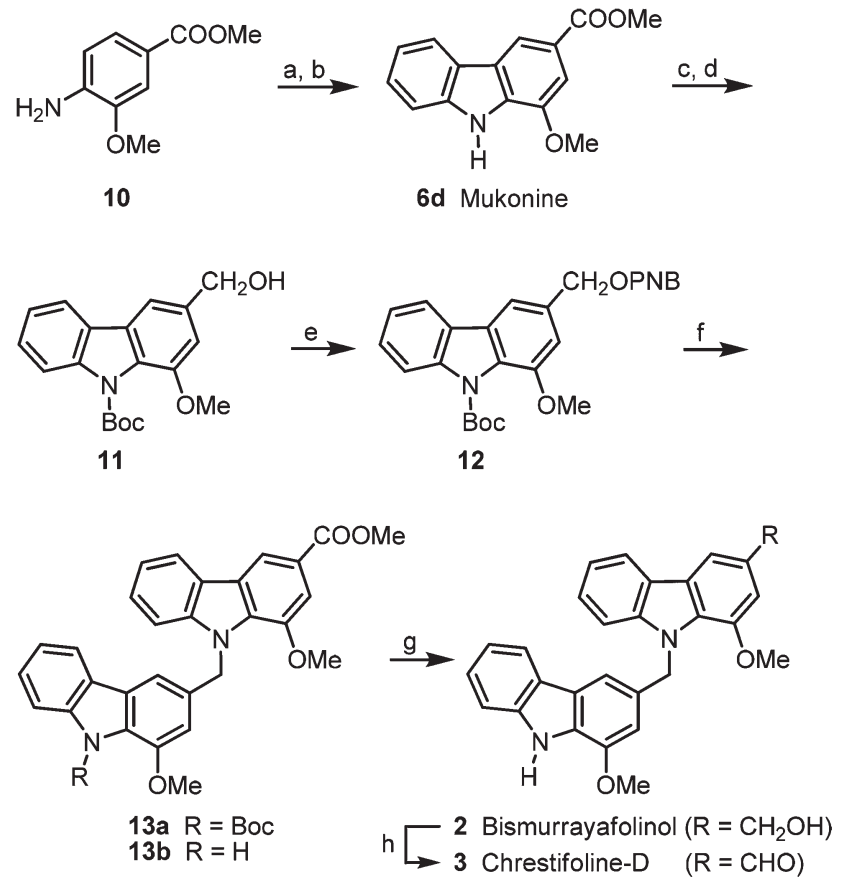

Scheme 2 Synthesis of bismurrayafolinol (2) and chrestifoline-D (3). Reagents and conditions: (a) 1.2 equiv. $\mathrm{PhBr}, 6 \mathrm{~mol} \% \mathrm{Pd}(\mathrm{OAc})_{2}, 12 \mathrm{~mol} \%$ SPhos, 1.4 equiv. $\mathrm{Cs}_{2} \mathrm{CO}_{3}$, toluene, reflux, $40 \mathrm{~h}, 100 \%$; (b) $10 \mathrm{~mol} \%$ $\mathrm{Pd}(\mathrm{OAc})_{2}, 10 \mathrm{~mol} \% \mathrm{~K}_{2} \mathrm{CO}_{3}$, PivOH, $115^{\circ} \mathrm{C}$, air, $14 \mathrm{~h}, 91 \%$; (c) 2 equiv. $\mathrm{Boc}_{2} \mathrm{O}$, 1 equiv. DMAP, MeCN, rt, $17 \mathrm{~h}, 97 \%$; (d) 3.2 equiv. DIBAL-H, $\mathrm{Et}_{2} \mathrm{O},-78{ }^{\circ} \mathrm{C}$, $3.5 \mathrm{~h}, 100 \%$; (e) 1.5 equiv. $p$ - $\left(\mathrm{NO}_{2}\right) \mathrm{C}_{6} \mathrm{H}_{4} \mathrm{COCl}, 1.5$ equiv. DMAP, $\mathrm{CH}_{2} \mathrm{Cl}_{2}, \mathrm{rt}$, $1.5 \mathrm{~h}, 100 \%$; (f) 1.3 equiv. mukonine (6d), 0.2 equiv. CuBr, 0.4 equiv. pyrrole-2-carboxylic acid, 4 equiv. $\mathrm{K}_{3} \mathrm{PO}_{4}$, DMSO, $110{ }^{\circ} \mathrm{C}, 40 \mathrm{~h}, 63 \% 13 \mathrm{~b}$; (g) 3.2 equiv. DIBAL-H, Et $2 \mathrm{O},-78^{\circ} \mathrm{C}, 4 \mathrm{~h}, 96 \%$; (h) 5 equiv. $\mathrm{MnO}_{2}, \mathrm{CH}_{2} \mathrm{Cl}_{2}$, rt, $24 \mathrm{~h}, 78 \%$.

the benzylic position of the koenoline derivative $11,^{7}$ the resulting compound should have sufficient stability in order to serve as the central intermediate en route to the methylenebridged biscarbazole alkaloids. Treatment of $\mathbf{1 1}$ with $p$-nitrobenzoyl chloride in the presence of stoichiometric amounts of DMAP afforded quantitatively the $p$-nitrobenzoate 12 . In contrast to the corresponding mesylate, ${ }^{7}$ the $p$-nitrobenzoate $\mathbf{1 2}$ is much more stable towards benzyl cation formation. Thus, the koenoline derivative $\mathbf{1 2}$ with an activated benzylic position is available in five steps and $88 \%$ overall yield and was subsequently used as a relay compound for the synthesis of the methylene-bridged biscarbazole alkaloids 1-5.

First, we envisaged a Buchwald-Hartwig coupling reaction of the $p$-nitrobenzoate $\mathbf{1 2}$ with mukonine (6d). Only a few methods have been described so far using transition metalcatalysed coupling reactions at the benzylic position. ${ }^{21}$ Reaction of $\mathbf{1 2}$ and $\mathbf{6} \mathbf{d}$ in the presence of catalytic amounts of palladium(II) acetate, rac-BINAP and stoichiometric amounts of caesium carbonate in toluene at reflux provided the desired biscarbazole 13a in 27\% yield along with the deprotected biscarbazole $\mathbf{1 3 b}$ in $35 \%$ yield (Scheme 2, Table 1 ). The concomitant partial removal of the Boc group could result either from a pericyclic reaction under thermal conditions ${ }^{22}$ or from a base-promoted saponification. Coupling of 12 and $\mathbf{6 d}$ under 
Table 1 Coupling of the $p$-nitrobenzoate 12 with mukonine $(6 \mathrm{~d})$

\begin{tabular}{ll}
\hline Reaction conditions & $\begin{array}{l}\text { Products, } \\
\text { yield (\%) }\end{array}$ \\
\hline 1.3 equiv. 6d, 10 mol\% $\mathrm{Pd}(\mathrm{OAc})_{2}, 10$ mol\% & $\mathbf{1 3 a}, 27 \%$; \\
rac-BINAP, 1.4 equiv. $\mathrm{Cs}_{2} \mathrm{CO}_{3}$, toluene, reflux, $4 \mathrm{~d}$. & $\mathbf{1 3 b}, 35 \%$ \\
1.3 equiv. $\mathbf{6 d}, 0.2$ equiv. $\mathrm{CuBr}_{0}, 4$ equiv. pyrrole- & $\mathbf{1 3 b}, 63 \%$ \\
2-carboxylic acid, 4 equiv. $\mathrm{K}_{3} \mathrm{PO}_{4}$, DMSO, $110^{\circ} \mathrm{C}, 40 \mathrm{~h}$. &
\end{tabular}

Ullmann conditions, using substoichiometric amounts of copper(I) bromide in the presence of pyrrole-2-carboxylic acid, ${ }^{23}$ led only to the deprotected biscarbazole 13b in $63 \%$ yield (see the Experimental procedure). Therefore, the Ullmann coupling reaction is superior for the present synthesis as it provides directly the biscarbazole $\mathbf{1 3 b}$ and thus avoids an additional deprotection step. Reduction of biscarbazole 13b with diisobutylaluminium hydride provided bismurrayafolinol (2) in 96\% yield. The spectroscopic data of 2 are in full agreement with those reported for the natural product.§ Reduction of 13b using lithium aluminium hydride afforded bismurrayafolinol (2) in $90 \%$ yield but did not lead to bismurrayafoline-A (1). Apparently, N-substituted carbazoles do not form the quinone imine methide intermediate required for the complete reduction to a 3-methylcarbazole, ${ }^{5 i, 13,24}$ and thus, further reduction of the 3-(hydroxymethyl)carbazole does not occur. Oxidation of bismurrayafolinol (2) with manganese(Iv) oxide $^{25,26}$ led to chrestifoline-D (3).§

Using the Ullmann-type coupling of the $p$-nitrobenzoate $\mathbf{1 2}$ with the appropriate carbazole building blocks $\mathbf{6 a}, 7 \mathbf{a}$ and $\mathbf{7 b}$,

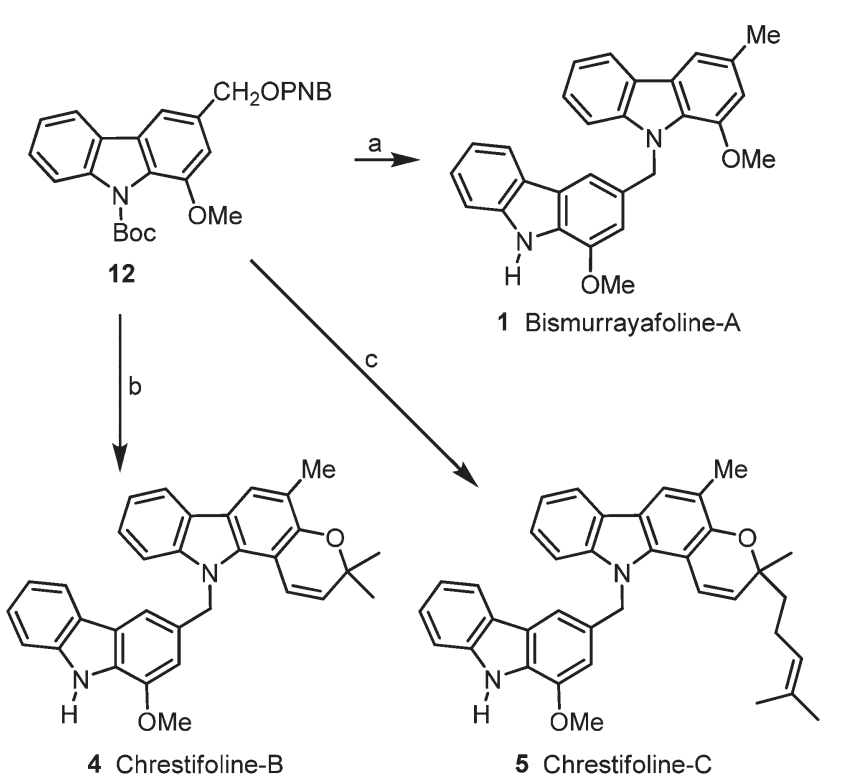

Scheme 3 Synthesis of bismurrayafoline-A (1), chrestifoline-B (4), and chrestifoline-C (5). Reagents and conditions: (a) 1.5 equiv. $6 a, 0.4$ equiv. $\mathrm{CuBr}, 0.8$ equiv. pyrrole-2-carboxylic acid, 4 equiv. $\mathrm{K}_{3} \mathrm{PO}_{4}, \mathrm{DMSO}$, $110{ }^{\circ} \mathrm{C}, 2 \mathrm{~d}, 46 \%$; (b) 1.5 equiv. $7 \mathrm{a}, 0.2$ equiv. $\mathrm{CuBr}, 0.4$ equiv. pyrrole-2carboxylic acid, 4 equiv. $\mathrm{K}_{3} \mathrm{PO}_{4}, \mathrm{DMSO}, 125{ }^{\circ} \mathrm{C}, 40 \mathrm{~h}, 41 \%$; (c) 1.5 equiv. 7b, 0.2 equiv. CuBr, 0.4 equiv. pyrrole-2-carboxylic acid, 4 equiv. $\mathrm{K}_{3} \mathrm{PO}_{4}$, DMSO, $120^{\circ} \mathrm{C}, 40 \mathrm{~h}, 32 \%$. the methylene-bridged biscarbazoles 1, 4 and 5 became directly available (Scheme 3).

Thus, reaction of murrayafoline-A $(\mathbf{6 a})^{8}$ with the $p$-nitrobenzoate 12 provided bismurrayafoline-A (1) in $46 \%$ yield. $\S$ The Ullmann-type coupling of the nitrobenzoate $\mathbf{1 2}$ with girinimbine (7a) $)^{20 c}$ afforded chrestifoline-B (4) and the reaction of 12 with mahanimbine (7b) ${ }^{20 c}$ provided ( \pm )-chrestifoline-C (5). $\S$ A comparison of the four Ullmann-type couplings described herein reveals that mukonine (6d), which obviously is more stable under the reaction conditions, provided the best yield (63\%) for the copper-induced $\mathrm{C}-\mathrm{N}$ bond formation with compound 12.

In conclusion, five naturally occurring methylene-bridged biscarbazole alkaloids were synthesised using an Ullmanntype coupling at the benzylic carbon atom of the relay compound $\mathbf{1 2}$ as the key reaction. Using the present route, the biscarbazole alkaloids 1-5 become available via short and efficient synthetic routes, bismurrayafoline-A (1): 6 steps, $41 \%$ overall yield; bismurrayafolinol (2): 7 steps, $53 \%$ overall yield; chrestifoline-D (3): 8 steps, $42 \%$ overall yield; chrestifoline-B (4): 6 steps, 36\% overall yield; and ( \pm -chrestifoline-C (5): 6 steps, $28 \%$ overall yield based on the arylamine 10. Chrestifoline-B (4) and ( \pm )-chrestifoline-C (5) have been obtained by total synthesis for the first time. Studies concerning the bioactivity of the biscarbazole alkaloids 1-5 are in progress.

\section{Experimental procedure}

Experimental procedure for the Ullmann-type coupling to the biscarbazole 13b:

A solution of the $p$-nitrobenzoate $12(66.6 \mathrm{mg}, 0.140 \mathrm{mmol})$, freshly dried potassium phosphate $(120 \mathrm{mg}, 0.566 \mathrm{mmol})$, mukonine (6d) (46.4 mg, $0.182 \mathrm{mmol}$ ), copper(I) bromide (4.0 $\mathrm{mg}, 28 \mu \mathrm{mol}$ ), and pyrrole-2-carboxylic acid $(6.2 \mathrm{mg}$, $56 \mu \mathrm{mol})$ in DMSO $(1 \mathrm{~mL})$ was heated at $110^{\circ} \mathrm{C}$ for $40 \mathrm{~h}$. Water $(1.5 \mathrm{~mL})$ and a saturated aqueous solution of ammonium chloride $(3 \mathrm{~mL})$ were added, the layers were separated and the aqueous layer was extracted three times with ethyl acetate. The combined organic layers were dried over magnesium sulfate and the solvents were removed under reduced pressure. Purification of the residue by flash chromatography on silica gel (gradient elution with petroleum ether-ethyl acetate, 19:1 to $7: 3)$ afforded the biscarbazole $\mathbf{1 3 b}(40.9 \mathrm{mg}, 63 \%)$ as a colourless solid; mp $152.5-153^{\circ} \mathrm{C} . \mathrm{UV}(\mathrm{MeOH}): \lambda=240$ (sh), 252 (sh), 270, 292 (sh), $325 \mathrm{~nm}$; IR (ATR): $\nu=3360,3055,2992,2949$, 2933, 2836, 1771, 1734, 1716, 1692, 1653, 1625, 1582, 1542, 1503, 1489, 1448, 1401, 1358, 1338, 1306, 1266, 1251, 1200, 1167, 1134, 1103, 1037, 1011, 991, 947, 906, 861, 837, 764, 729, 694, 665, $613 \mathrm{~cm}^{-1} ;{ }^{1} \mathrm{H}$ NMR (500 MHz, $\left.\mathrm{CDCl}_{3}\right): \delta=3.81(\mathrm{~s}, 3$ H), $3.99(\mathrm{~s}, 3 \mathrm{H}), 4.02(\mathrm{~s}, 3 \mathrm{H}), 6.05(\mathrm{~s}, 2 \mathrm{H}), 6.76(\mathrm{~d}, J=0.8 \mathrm{~Hz}$, $1 \mathrm{H}), 7.17$ (ddd, $J=7.9 \mathrm{~Hz}, 6.9 \mathrm{~Hz}, 1.1 \mathrm{~Hz}, 1 \mathrm{H}$ ), 7.27 (ddd, $J=$ $7.8 \mathrm{~Hz}, 7.0 \mathrm{~Hz}, 0.8 \mathrm{~Hz}, 1 \mathrm{H}), 7.37$ (ddd, $J=8.1 \mathrm{~Hz}, 7.0 \mathrm{~Hz}$, $1.1 \mathrm{~Hz}, 1 \mathrm{H}), 7.40-7.44(\mathrm{~m}, 2 \mathrm{H}), 7.497(\mathrm{~d}, J=8.1 \mathrm{~Hz}, 1 \mathrm{H})$, $7.500(\mathrm{~s}, 1 \mathrm{H}), 7.66(\mathrm{~d}, J=1.3 \mathrm{~Hz}, 1 \mathrm{H}), 7.93(\mathrm{~d}, J=7.8 \mathrm{~Hz}, 1 \mathrm{H})$, $8.14(\mathrm{~d}, J=7.8 \mathrm{~Hz}, 1 \mathrm{H}), 8.20(\mathrm{br} \mathrm{s}, 1 \mathrm{H}), 8.54(\mathrm{~d}, J=1.3 \mathrm{~Hz}$, 
$1 \mathrm{H}) ;{ }^{13} \mathrm{C}$ NMR and DEPT (125 $\left.\mathrm{MHz}, \mathrm{CDCl}_{3}\right): \delta=49.76\left(\mathrm{CH}_{2}\right)$, $52.18\left(\mathrm{CH}_{3}\right), 55.51\left(\mathrm{CH}_{3}\right), 56.08\left(\mathrm{CH}_{3}\right), 104.89(\mathrm{CH}), 108.20$ $(\mathrm{CH}), 110.38(\mathrm{CH}), 110.99(\mathrm{CH}), 111.09(\mathrm{CH}), 116.38(\mathrm{CH})$, $119.46(\mathrm{CH}), 120.23(\mathrm{CH}), 120.56(\mathrm{CH}), 120.66(\mathrm{CH}), 121.50(\mathrm{C})$ 123.51 (C), 123.65 (C), 124.17 (C), 124.55 (C), 125.88 (CH), 126.48 (CH), 129.13 (C), 130.65 (C), 133.19 (C), 139.49 (C), 141.76 (C), 145.87 (C), 146.57 (C), 168.03 (C); ESI-MS (+50 V): $m / z=487[\mathrm{M}+\mathrm{Na}]^{+},(-100 \mathrm{~V}): m / z=463[\mathrm{M}-\mathrm{H}]^{-} ; \mathrm{MS}(\mathrm{EI}):$ $m / z(\%)=464\left(26, \mathbf{M}^{+}\right), 255$ (32), 240 (8), 224 (8), 210 (100), 167 (11); HRMS: $m / z$ calcd for $\mathrm{C}_{29} \mathrm{H}_{24} \mathrm{~N}_{2} \mathrm{O}_{4}\left(\mathrm{M}^{+}\right)$: 464.1736; found: 464.1741.

\section{Notes and references}

§ Bismurrayafoline-A (1): Light brownish solid, mp 209-210 ${ }^{\circ} \mathrm{C}$; UV (MeOH): $\lambda=$ 224, 243, 251, 262 (sh), 282, 292, 323 (sh), 338, 352 (sh) nm; MS (EI): $m / z(\%)=$ $420\left(\mathrm{M}^{+}, 40\right), 210$ (100).

Bismurrayafolinol (2): Colourless solid, mp $120-121.5^{\circ} \mathrm{C}$; UV (MeOH): $\lambda=225$, 243, 252, 261 (sh), 281, 292, 331, 343 (sh) nm; MS (EI): $m / z(\%)=436\left(\mathrm{M}^{+}, 12\right)$, 210 (100).

Chrestifoline-D (3): Colourless solid, mp 163.5-164 ${ }^{\circ} \mathrm{C}$; UV (MeOH): $\lambda=222$, 242, 251, 275, 291, 338, 346 (sh) nm; MS (EI): $m / z(\%)=434$ (M+1 22), 210 (100).

Chrestifoline-B (4): Light brownish solid, mp 106-107 ${ }^{\circ} \mathrm{C}$; UV (MeOH): $\lambda=227$ (sh), 239, 251 (sh), 258 (sh), 290, 325, 338, 358 (sh) nm; ESI-MS (-10 V): $\mathrm{m} / \mathrm{z}=$ $471[\mathrm{M}-\mathrm{H}]^{-}$.

( \pm )-Chrestifoline-C (5): Light brownish solid, mp $90^{\circ} \mathrm{C}$; UV (MeOH): $\lambda=228$ (sh), 242, 251 (sh), 282 (sh), 290, 327, 340, $360 \mathrm{~nm}$; ESI-MS (+10 V): $\mathrm{m} / z=541$ $[\mathrm{M}+\mathrm{H}]^{+}$.

For the ${ }^{1} \mathrm{H}$ and ${ }^{13} \mathrm{C}$ NMR spectra of the biscarbazoles 1-5, see: ESI.+

1 (a) H.-J. Knölker and K. R. Reddy, Chem. Rev., 2002, 102, 4303; (b) H.-J. Knölker and K. R. Reddy, in The Alkaloids, ed. G. A. Cordell, Academic Press, Amsterdam, 2008, vol. 65, p. 1; (c) A. W. Schmidt, K. R. Reddy and H.-J. Knölker, Chem. Rev., 2012, 112, 3193.

2 (a) H.-J. Knölker, Top. Curr. Chem., 2005, 244, 115; (b) I. Bauer and H.-J. Knölker, Top. Curr. Chem., 2012, 309, 203.

3 (a) D. P. Chakraborty and S. Roy, in Progress in the Chemistry of Organic Natural Products, ed. W. Herz, H. Grisebach, G. W. Kirby, W. Steglich and C. Tamm, Springer-Verlag, Wien, 1991, vol. 57, p. 71; (b) D. P. Chakraborty, in The Alkaloids, ed. G. A. Cordell, Academic Press, New York, 1993, vol. 44, p. 257; (c) C. J. Moody, Synlett, 1994, 681; (d) D. P. Chakraborty and S. Roy, in Progress in the Chemistry of Organic Natural Products, ed. W. Herz, H. Grisebach, G. W. Kirby, W. Steglich and C. Tamm, Springer-Verlag, Wien, 2003, vol. 85, p. 125.

4 (a) H. Furukawa, Trends Heterocycl. Chem., 1993, 3, 185; (b) S. Tasler and G. Bringmann, Chem. Rec., 2002, 2, 113.

5 Reviews: (a) H.-J. Knölker, Curr. Org. Synth., 2004, 1, 309; (b) H.-J. Knölker, Chem. Lett., 2009, 38, 8; applications: (c) H.-J. Knölker and N. O'Sullivan, Tetrahedron, 1994, 50, 10893; (d) H.-J. Knölker and K. R. Reddy, Heterocycles, 2003, 60, 1049; (e) R. Forke, A. Jäger and H.-J. Knölker, Org. Biomol. Chem., 2008, 6, 2481; $(f)$ R. Forke, M. P. Krahl, F. Däbritz, A. Jäger and H.-J. Knölker, Synlett, 2008, 1870; $(g)$ T. Gensch, M. Rönnefahrt, R. Czerwonka, A. Jäger,
O. Kataeva, I. Bauer and H.-J. Knölker, Chem. - Eur. J., 2012, 18, 770; $(h)$ L. Huet, R. Forke, A. Jäger and H.-J. Knölker, Synlett, 2012, 1230; (i) C. Börger and H.-J. Knölker, Tetrahedron, 2012, 68, 6727.

6 (a) V. P. Kumar, K. K. Gruner, O. Kataeva and H.-J. Knölker, Angew. Chem., 2013, 125, 11279, (Angew. Chem. Int. Ed., 2013, 52, 11073); (b) C. Börger, A. W. Schmidt and H.-J. Knölker, Synlett, 2014, DOI: 10.1055/s-0033-1338621.

7 C. Börger, M. P. Krahl, M. Gruner, O. Kataeva and H.-J. Knölker, Org. Biomol. Chem., 2012, 10, 5189.

8 C. Börger, O. Kataeva and H.-J. Knölker, Org. Biomol. Chem., 2012, 10, 7269.

9 (a) A. S. Guram, R. A. Rennels and S. L. Buchwald, Angew. Chem., 1995, 107, 1456, (Angew. Chem. Int. Ed. Engl., 1995, 34, 1348); (b) J. Louie and J. F. Hartwig, Tetrahedron Lett., 1995, 36, 3609; (c) S. Shekhar, P. Ryberg, J. F. Hartwig, J. S. Mathew, D. G. Blackmond, E. R. Strieter and S. L. Buchwald, J. Am. Chem. Soc., 2006, 128, 3584; (d) B. Schlummer and U. Scholz, Adv. Synth. Catal., 2004, 346, 1599.

10 (a) F. Ullmann, Ber. Dtsch. Chem. Ges., 1903, 36, 2382; (b) F. Ullmann, Ber. Dtsch. Chem. Ges., 1904, 37, 853; (c) I. Goldberg, Ber. Dtsch. Chem. Ges., 1906, 39, 1691; (d) S. V. Ley and A. W. Thomas, Angew. Chem., 2003, 115, 5558, (Angew. Chem. Int. Ed., 2003, 42, 5400).

11 H. Furukawa, T.-S. Wu and T. Ohta, Chem. Pharm. Bull., 1983, 31, 4202.

12 M. Itoigawa, Y. Kashiwada, C. Ito, H. Furukawa, Y. Tachibana, K. F. Bastow and K.-H. Lee, J. Nat. Prod., 2000, 63, 893.

13 G. Bringmann and S. Tasler, Tetrahedron, 2001, 57, 2337.

14 C. Ito, T.-S. Wu and H. Furukawa, Chem. Pharm. Bull., 1987, 35,450 .

15 C. Ito, N. Okahana, T.-S. Wu, M.-L. Wang, J.-S. Lai, C.-S. Kuoh and H. Furukawa, Chem. Pharm. Bull., 1992, 40, 230.

16 C. Ito, T.-S. Wu and H. Furukawa, Chem. Pharm. Bull., 1990, 38, 1143.

17 D. P. Chakraborty, B. K. Barman and P. K. Bose, Sci. Cult., 1964, 30, 445.

18 D. P. Chakraborty, K. C. Das and P. K. Bose, Sci. Cult., 1966, 32, 83 .

19 (a) H.-J. Knölker and M. Bauermeister, J. Chem. Soc., Chem. Commun., 1990, 664; (b) H.-J. Knölker and M. Bauermeister, Tetrahedron, 1993, 49, 11221; (c) H.-J. Knölker and M. Wolpert, Tetrahedron Lett., 1997, 38, 533; (d) H.-J. Knölker and M. Wolpert, Tetrahedron, 2003, 59, 5317.

20 (a) K. K. Gruner and H.-J. Knölker, Org. Biomol. Chem., 2008, 6, 3902; (b) K. K. Gruner, T. Hopfmann, K. Matsumoto, A. Jäger, T. Katsuki and H.-J. Knölker, Org. Biomol. Chem., 2011, 9, 2057; (c) R. Hesse, K. K. Gruner, O. Kataeva, A. W. Schmidt and H.-J. Knölker, Chem. - Eur. J., 2013, 19, 14098. 
21 See for example: (a) R. A. Earley and M. J. Gallagher, J. Chem. Soc. C, 1970, 158; (b) U. Nettekoven and J. F. Hartwig, J. Am. Chem. Soc., 2002, 124, 1166; (c) S. L. Marquard, D. C. Rosenfeld and J. F. Hartwig, Angew. Chem., 2010, 122, 805, (Angew. Chem. Int. Ed., 2010, 49, 793).

22 (a) V. H. Rawal and M. P. Cava, Tetrahedron Lett., 1985, 26, 6141; (b) K. E. Knott, S. Auschill, A. Jäger and H.-J. Knölker, Chem. Commun., 2009, 1467.
23 R. A. Altman, K. W. Anderson and S. L. Buchwald, J. Org. Chem., 2008, 73, 5167.

24 D. P. Chakraborty, S. Roy and A. K. Dutta, J. Indian Chem. Soc., 1987, 64, 215.

25 (a) A. J. Fatiadi, Synthesis, 1976, 65; (b) H.-J. Knölker, J. Prakt. Chem., 1995, 337, 75.

26 Manganese dioxide (precipitated, active) from Merck (art. 805958). 